\title{
A PANDEMIA À LUZ DA FRATERNIDADE
}

Munir Cury ${ }^{3}$

DOI: https://doi.org/10.47306/978-65-88213-03-2.22-31

29 de Junho de 2020, 7:00 horas. Inicio o meu trabalho, surpreso e preocupado com o crescente número de mortes provocadas pelo coronavírus no Brasil e no mundo. Na verdade, após quatro meses de seguidas e chocantes notícias, já não deveria me escandalizar, porém, diante dos 58.385 óbitos entre nós e 500.000 nos quatro continentes, somados às palavras do diretor geral da Organização Mundial da Saúde (OMS), Tedros Adhanom Ghebreyesus, alertando que "a pandemia está longe de terminar" e que o "pior ainda está por vir", permaneci paralisado por alguns momentos. Não bastasse esse doloroso contexto, vivemos no nosso país momentos de instabilidade política com conseqüências nefastas para o povo e a economia; a falta de diretriz sanitária que nos tranqüilize, o desemprego que nos aflige, e os desnecessários confrontos e desgastes na esfera federal, são amargos ingredientes que causam alarme e pânico na população.

No entanto, procurando percorrer a história da humanidade, com os seus percalços e sucessos, as suas vitórias e fracassos, a sua sujeição a calamidades e como as enfrentou, os seus limites e a sua superação, constatei a existência de um fio condutor que moveu grandes homens nos mais variados campos de atuação, desde renomados pensadores, passando pela filosofia, pela literatura, a música, a arte em geral, que conseguiram transformar tragédias pessoais em íntima harmonia, a angústia e a tristeza em texturas coloridas e vibrantes, a proximidade da morte em iniciativas de solidariedade ao próximo.

São também situações semelhantes com as quais nos deparamos atualmente diante da pandemia do coronavírus, ou seja, tragédias pessoais e familiares que se multiplicam, funerais coletivos e impessoais, angústias e melancolias por não poderem acompanhar seus familiares nos leitos hospitalares, a proximidade da morte que nunca como hoje está presente e iminente.

Pelo grande bálsamo e benefício da minha convivência pessoal com esses históricos homens e mulheres, proponho ao leitor que os visitemos e nos alimentemos com esse néctar transformador do desgosto e do pesar em uma energia construtora de empatia.

Retrocedamos alguns milênios na história da humanidade e nos encontremos com Davi

\footnotetext{
${ }^{3}$ Procurador de Justiça aposentado do Ministério Público de São Paulo.
} 
(1040 a.c.- 970 a.c.), guerreiro, profeta e rei do povo de Israel durante quarenta anos, entre 1006 e 966 a.c., que conseguiu lançar as bases para a formação de um verdadeiro estado hebraico. Imortalizado por Michelângelo na conhecida escultura exposta na Galeria da Academia de Belas Artes de Florença (Itália), dotado de grande vigor na sua juventude, em guerra contra os filisteus, matou o gigante Golias. Durante o período de maior prosperidade do reino de Israel, Davi experimentou a sua queda mais amarga ao cometer adultério com Betsabéia, mulher de Urias, seu general, a quem mandou matar em seguida. Por essa razão foi duramente repreendido pelo profeta Natã, que o condenou, ao vaticinar: "a espada nunca se afastará de sua casa". Embora tenha posteriormente se casado com Betsabéia, com ela teve um filho que faleceu sete dias após o nascimento. Tais episódios são conhecidos como “o pecado de Davi”, sentimento de angústia e sofrimento que o acompanhou durante toda a vida; no entanto, habilidoso na música e harpista por excelência, Daví se imortalizou em inúmeros salmos, reconhecidos como obras poéticas primorosas, além de profundos textos espirituais que glorificam a vida e a beleza.

Ainda em milênios passados, reflitamos em torno de algumas palavras do filósofo grego Aristóteles (385 a.c.-323 a.c.), de origem aristocrática e que causou admiração pelo seu comportamento requintado e pela sua inteligência. Desde a sua adolescência entrou para a academia de seu mestre, Platão, chegando a substituí-lo após a sua morte. Não foi somente filósofo, mas também um apaixonado pela física, pela metafísica, a música, a poesia e o drama, a retórica e o governo, a biologia e a zoologia. Cabe-lhe essa profética expressão: "A natureza não faz nada em vão". Permita-me o leitor insistir que se trata de uma visão profética, pois, se revelada no longínquo período anterior a Cristo, permanece atual e resistente ao tempo, à cultura, às pesquisas científicas do mundo moderno, às correntes de pensamento que se manifestaram em várias etapas do conhecimento humano, enfim, "a natureza não faz nada em vão" sedimentou-se como verdade incontestável.

Perguntemo-nos: o que a natureza quer nos dizer frente a esse quadro verdadeiramente dantesco da pandemia? Com certeza, nas entrelinhas dessa incontida insegurança e pavor, há uma mensagem, se não explícita ao menos intuitiva, de que os homens devem mudar o rumo de suas vidas, priorizar valores e comportamentos, convencerem-se que os pequenos atos podem se transformar em grandiosos se movidos pela generosidade, que a compaixão é a iguaria da realização pessoal, que a ternura e o afeto não são privilégios femininos, mas a bandeira de homens sensíveis ao próximo, compreenderem que o perdão não é mera desculpa, mas o reinício de um relacionamento amadurecido pela compreensão. Acaso esse disseminado pavor não nos interpela a deixarmos de ser sociedade para nos transformarmos em comunidade nacional ou internacional, ligados por vínculos de solidariedade e fraternidade? 
Voltemo-nos desta feita para o universo do pensamento, encontrando-nos com MICHEL DE MONTAIGNE (1533-1592), escritor, filósofo e humanista que produziu uma única obra marcada pela dúvida e pelo ceticismo. Trata-se de Os Ensaios, cuja proposta seria a abordagem de assuntos que considerasse relevantes sem, no entanto, uma preocupação formal ou estética. No seu capítulo XX, que se intitula "Filosofia uma aprendizagem para morrer", MONTAIGNE reflete sobre a morte como o único ato de liberdade do ser humano, ou, nas suas palavras, "meditar sobre a morte é meditar sobre a liberdade".

Seguramente poderemos concluir com MONTAIGNE que a morte é algo inevitável, que ela nos ensina a viver, não importando se vivemos muitos anos, mas o que importa é a forma e a maneira como se aproveitou esse privilégio que é a vida.

PAUL RICOEUR (1913-2005), por sua vez, é um dos mais respeitados filósofos franceses do século XX. Em 1939, em pleno combate na Segunda Guerra Mundial e servindo como oficial de reserva, foi preso pelos nazistas e enviado a um campo de concentração na Polônia, onde conviveu com inúmeros intelectuais. RICOEUR, avaliando esse período de cinco anos de cativeiro, assim se expressa em uma de suas obras: "foram anos frutuosos tanto do ponto de vista humano como intelectual'. Anos depois, envolvido pela dor do suicídio de seu filho e a doença degenerativa de sua esposa, surpreendentemente, essa foi a etapa mais produtiva do filósofo, ocasião em que lançou uma de suas obras mais conhecidas, "Soi-même comme un autre" (O si-mesmo como o outro), na qual aborda temas como a reciprocidade no relacionamento dos seres humanos. Ao acompanhar e considerar a trajetória do homem enquanto ser social, RICOEUR conclui que: “nós somos hoje responsáveis pelo futuro mais longínquo da humanidade", daí podermos deduzir que a célula de ambiente que cada homem constrói em sua vida, se pautada pela solidariedade e pela compaixão, terá inevitavelmente reflexos no tecido social, o mesmo acontecendo com o inverso. E aqui nos servimos da metáfora dos círculos concêntricos que se formam em torno de uma pedra atirada ao lago, os quais se multiplicam numericamente, porém, a sua articulação inicial está na pedra lançada.

Mudemos a rota de nossas reflexões e ingressemos no cenário da arte da fantasia e da palavra, convivendo com alguns mestres da literatura e nos maravilhemos com suas poesias, romances, dramas, contos ou lendas.

WILLIAM SHAKESPEARE (1564-1616), figura cultural mais representativa do Reino Unido, dramaturgo e poeta, é considerado um dos mais influentes representantes da literatura mundial. Na sua famosa "Tragédia de Hamlet", o personagem central se apresenta com uma caveira nas mãos declamando a famosa frase "to be or not to be, that is the question", enquanto vive cenários de morte, infortúnios, opressões e afrontas. Seguindo a linha de parte de suas 
obras que se caracterizam pelo conceito filosófico sobre a vida e a morte, escreveu onze tragédias, entre elas as também consagradas pelo público "Otelo", "Rei Lear", "Macbeth", e "Antonio e Cleópatra", nas quais se evidenciam o pessimismo, a crítica ácida, a análise psicológica dura e profunda. Talvez a sua obra mais popularmente conhecida seja "Romeu e Julieta", considerada por especialistas como um romance trágico, no qual a morte é uma espécie de consumação do amor. Essas obras representam o resultado e a expressão da sua personalidade melancólica, introspectiva e sofredora, marcada por situações de dores e conflitos.

No entanto, SHAKESPEARE se lançou igualmente em comédias e sonetos cheios de jogos encantadores de palavras, como em "O Sonho de uma Noite de Verão" e "O Mercador de Veneza", onde o tema dominante é o amor, em ambiente feérico e onírico, com cenas iluminadas e coloridas.

Tais contrastes nos permitem deduzir que os momentos trágicos de suas obras não refletem uma única característica pessoal, pois se transmudam em encantamentos e doces cenas idílicas, ricas de sentimentos e vibrações.

São suas essas verdadeiras confissões: "É melhor viver sem felicidade do que sem amor", e ainda, "Um amor arruinado, ao ser reconstruido, cresce muito mais belo, sólido e maior”, prosseguindo com sabedoria “A vida é muito curta. Passar esse momento de forma vil seria um desperdício", para concluir afirmando que "a alegria evita mil males e prolonga a vida".

A passos largos, avancemos no tempo para encontrar o dramaturgo, romancista, ensaísta e poeta patrício, considerado um preeminente defensor da cultura nordestina do Brasil, ARIANO SUASSUNA (1927-2014). Com a revolução de 1930, seu pai foi assassinado por motivos políticos no Rio de Janeiro, onde a família residia na ocasião. O próprio ARIANO SUASSUNA reconhecia que o assassinato de seu pai ocupava posição marcante em sua inquietação criadora. Tanto que, no seu discurso de posse na Academia Brasileira de Letras, confessou: "Posso dizer que, como escritor, eu sou de certa forma aquele mesmo menino que, perdendo o pai assassinado no dia 9 de outubro de 1930, passou o resto da vida tentando protestar contra sua morte através do que faço e do que escrevo, oferecendo-lhe esta precária compensação e, ao mesmo tempo, buscando recuperar a sua imagem através da lembrança do depoimento dos outros, das palavras que o pai deixou”.

Deixou inúmeras obras, com seu cunho espirituoso e apaixonado, traduzidas para o inglês, francês, espanhol, alemão, holandês, italiano e polonês. O "Auto da Compadecida", é sua obra mais conhecida e aclamada, adaptada para o cinema e a televisão, e reconhecida pela 
crítica teatral como o texto mais popular do teatro moderno brasileiro. Nela, em estilo simples, o humor e a sátira unem-se num tom caricatural, porém, com sentido moralizante

Dotado de espírito dinâmico e renovador, em 1970 criou e dirigiu o Movimento Armorial, com o objetivo de realizar uma arte brasileira erudita a partir de raízes populares, como os folhetos de cordel, os cantadores e as festas tradicionais.

Com sua fértil imaginação, deixou-nos como legado: "o sonho é que leva a gente para a frente. Se a gente for seguir a razão, fica aquietado, acomodado".

O sonho é o distintivo de homens que marcaram a história da humanidade. Lembremonos do ativista político estadunidense MARTIN LUTHER KING, assassinado em 1968, amplamente conhecido pela sua luta objetivando a garantia dos direitos políticos através da não-violência e desobediência civil, inspirado no ativismo não-violento de MAHATMA GANDHI. Em seu discurso público no qual destacava a necessidade de união e coexistência harmoniosa entre negros e brancos, pronunciou a famosa frase: "I have a dream", que marcou fortemente a sua personalidade e desejo de justiça. Confirmemos igualmente esse natural sonho do ser humano com as palavras do célebre escritor francês ANDRÉ MALRAUX (1901-1976): “A morte só ganha importância à medida que nos faz refletir sobre o valor da vida".

Mudemos de ambientação, passando da arte da literatura para o mundo da magia do pincel e do cinzel, onde cores, luzes e formas expressam fortemente a personalidade do artista, verdadeiro mago que metamorfoseia seus modelos e suas fantasias em obras que encantam a sensibilidade e delimitam épocas da história.

Aproximemo-nos inicialmente diante das obras de MICHELANGELO (1475-1564), famoso escultor, pintor, poeta e arquiteto italiano, considerado um dos grandes representantes do renascimento italiano que, ainda em vida foi considerado o maior artista de eu tempo, tanto que o chamavam de o divino. É autor da famosa Pietá, escultura exposta na Basílica de São Pedro (Vaticano). Dotado de temperamento forte, antissocial, passional e violento, excêntrico e melancólico, MICHELANGELO, consciente ou inconscientemente, transformou as suas grandes contradições em famosas obras expostas em museus de vários países. Durante a sua vida de escultor recebeu um convite para pintar o teto da capela Sistina (Vaticano), mas inicialmente recusou a proposta exatamente por ser escultor, mas, diante da insistência do proponente, acabou aderindo e iniciou os trabalhos que duraram quatro anos, de 1508 a 1512 . O teto da capela Sistina contém nove painéis, porém, no momento nos interessa a cena de Noé e o dilúvio, na qual o artista retrata a tragédia dessa fase com cores fortes, personagens em desespero, águas revoltas, ventos terríveis, ondas mortais e perigo iminente. Prossigamos com o convite formulado a MICHELANGELO vinte e quatro anos depois de pintar o teto da capela, 
desta feita para decorar a parede atrás da mesma. Assim surgiu o famoso afresco Juizo Final, obra inspirada em trechos da Bíblia e da Divina Comédia, de Dante Alighieri, retratando brigas e lutas entre personagens e anjos, cenas de pessoas despejadas no inferno, enroladas em serpentes e, no centro desse quadro tumultuoso chama a atenção uma figura humana que parece ter desistido de lutar por ter compreendido o seu trágico destino. Destaca-se na parte superior a figura de Jesus Cristo, apresentado de forma viril e forte, cheio de luz e poder, porém, com as marcas dos pregos. Paralelamente a essas cenas impactantes, surgem no teto figuras serenas, cheias de paz, claridade e brilho, como o Deus Criador e os profetas.

Como considerar essas extremas contradições entre cenas de chocante violência, agressões e combates de um lado, e de outro, a paz e a suavidade lançadas na cor pastel emitindo uma sutileza branda e delicada, senão atribuindo à ímpar genialidade de MICHELANGELO, que conseguiu sublimar seu tumulto interior em beleza, candura e pureza e, ao final, maravilhar os sentimentos da humanidade?

Visitemos agora uma artista plástica brasileira, onde encontramos a paulista ANITA MALFATTI (1889-1964), que teve um papel preponderante em um dos acontecimentos mais importantes do modernismo, a Semana de Arte Moderna. ANITA nasceu com uma atrofia no braço direito e teve que aprender a usar a mão esquerda em todas as suas atividades. Aos treze anos de idade, desnorteada e sem qualquer rumo na vida, resolveu se suicidar, deitando-se nos dormentes de uma linha férrea. São suas essas palavras: "foi uma coisa horrível, indescritivel; barulho ensurdecedor, temperatura asfixiante; eu via cores, cores e cores riscando o espaço, cores que eu desejaria ficar para sempre na retina." E conclui: "foi uma revelação: voltei decidida a me dedicar à pintura. " Iniciou-se, assim, a partir da convivência com a proximidade da morte, a trajetória de uma artista que utilizou cores puras e vibrantes para expressar temas do cotidiano, colocando toda a sua criatividade em pincéis que imprimiram a sua paixão pela beleza, demonstrando que a limitação de suas mãos não a impediam de manifestar o encantamento pela natureza ou por figuras humanas. Expôs suas obras não só no Brasil, como também em Berlim, Paris e Nova Iorque, destacando-se: "O homem amarelo", "A onda", "Dora, rainha do frevo", entre outras.

Respeitadas as proporções, a vida de ANITA MALFATTI pode se comparar com a dos sobreviventes do holocausto nazista, como uma forte demonstração de que os desafios que nos são reservados podem ser superados e continuarmos a completar a nossa história convivendo com os espinhos de forma que não nos machuquem.

Sintamos agora o nosso espírito se elevar pela lembrança de inesquecíveis concertos e peças de MOZART (1756-1791) que, embora com o seu espírito melancólico e recolhido, 
produziu sinfonias alegres e óperas comoventes. A sua famosa Requiem ou missa fúnebre, foi deixada incompleta em razão de sua morte prematura aos 35 anos, mas é considerada por especialistas a maior expressão clássica da liturgia, revestindo-se de momentos de trágica sonoridade, instrumentalização profunda, cores dramáticas e sofridas, certamente expressão da sua personalidade triste e amargurada. Como dissemos, sua alma se transformou ao compor sinfonias, músicas de câmera, piano e minuetos que comunicam a leveza e a magia da arte. Entre elas, a famosa A Flauta Mágica, na qual os conceitos de liberdade, igualdade e fraternidade transparecem em vários momentos.

Consideremos desta feita um dos maiores intérpretes de JOHANN SEBASTIAN BACH, o pianista e maestro paulistano JOÃO CARLOS GANDRA DA SILVA MARTINS, mais conhecido como JOÃO CARLOS MARTINS (25/06/1940), que conduziu essas oito décadas de vida como um maestro na arte da superação, tendo agido heroicamente ao longo da sua existência, demonstrando fé na música e no amanhã. Assim é que, já em 1965, jogando no Central Park (Nova Iorque), sofreu uma queda que perfurou seu braço direito na altura do cotovelo, provocando atrofia em três dedos, o que não o impediu de continuar tocando, embora com dificuldade, até os trinta anos. Aclamado nacional e internacionalmente, nesse ínterim desenvolveu distúrbios ósteomusculares que o fizeram abandonar o palco mais de uma vez. Persistente, não desistiu da carreira musical e fez várias adaptações para continuar tocando. No ano de 1995, em um assalto na cidade de Sofia (Bulgária) foi golpeado na cabeça com uma barra de ferro, provocando seqüela neurológica que comprometeu o membro superior direito; submeteu-se, em seguida a trabalhos de reprogramação cerebral para conseguir movimentar a mão direita que, no entanto, redundaram em novas seqüelas no braço direito e na fala, depois superadas. Com o correr dos anos, desenvolveu no membro superior saudável uma nova contratura com o espessamento da fáscia palmar. Nova cirurgia, desta feita sem sucesso, que o inviabilizou de tocar piano. Passou, então, a reger as orquestras mais famosas do mundo, demonstrando a sua persistente paixão pela música. Não bastassem essas limitações, em 2012, submeteu-se a uma nova cirurgia no cérebro para recuperar os movimentos da mão esquerda, já que não a abria há dez anos. Finalmente, em 2020 voltou a tocar com as duas mãos, mas, desta vez, com a ajuda de uma luva biônica. Nessa ocasião, movido por grande e justificada emoção, exclamou: "é a primeira vez em vinte e dois anos que coloco os dez dedos no teclado."

Recomeçar, recomeçar sempre, não são somente palavras, mas sobretudo condutas que dão sentido à existência humana, que revigoram as forças para continuarmos o combate que nos é reservado, contribuindo para o crescimento pessoal e social. 
Na música popular brasileira, chama-nos a atenção DORIVAL CAYMMI (30/04/191416/8/2008). Sua neta Stella Caymmi, no livro sobre o avô O mar e o tempo, conta que em 1943, já conhecido desde 1938 por O que é que a baiana tem? gravado por Carmem Miranda, procurou alguns amigos revelando-lhes o sonho de estudar música, pois achava que não podia ser um músico completo se não pudesse ler partituras. Mas, temeroso que pudesse perder a sua espontaneidade, "recolheu o chapéu", nas palavras de neta, e foi compor do jeito que estava acostumado. CAYMMI apresenta lamentos em sua composição $E$ doce morrer no mar, com a letra: É doce morrer no mar, nas ondas verdes do mar. É doce morrer no mar, nas ondas verdes do mar. A noite que ele não veio foi de tristeza prá mim, Saveiro voltou sozinho, triste noite foi prá mim. É doce morrer no mar ..., e prossegue entoando a triste história de Saveiro, o marinheiro bonito que a sereia do mar levou e fez sua cama de noivo no colo de Iemanjá. Também na canção A jangada voltou só, CAYMMI entoa abatimento, melancolia e dor, nos versos: A jangada saiu com Chico Ferreira Bento, a jangada voltou só. Com certeza foi lá fora um pé de vento, a jangada voltou só. No entanto, sabemos que não só de tristeza viveu CAYMMI, bastando recordar Rosa morena e a já citada $O$ que é que a baiana tem? ou ainda Você já foi à Bahia?, A lenda de Abaeté, entre tantas outras canções.

O cancioneiro popular de CAYMMI revela a beleza da dor transformada em amor, alegria, entusiasmo e arrebatamento pelo cotidiano, cotidiano esse onde se encontram as pequenas pedras para composição do grande mosaico da felicidade humana.

Tenho diante de mim um poema, na realidade, uma profunda oração da carismática pensadora italiana CHIARA LUBICH, escrito em outubro de 1949, no período da reconstrução da cidade de Roma, após a Segunda Guerra Mundial. Com um olhar sociológico, ela constata os dolorosos contrastes desse período, diante do povo sem trabalho, a falta de alimentos, moradias escassas, numerosos migrantes, enfim, uma cidade degradada. Assim compôs com suas sábias palavras Resurrezione di Roma, em português, Ressurreição de Roma, onde a autora conclui, com a costumeira sabedoria, que "é necessário fazer renascer o Amor, conservá-lo vivo em nós mesmos e difundi-lo na sociedade como semente de vida, e, assim, ressuscitar os mortos". Trata-se de um olhar que, absorvendo a realidade tal qual ela é, vai além da aparência, ultrapassando o mero assistencialismo, sendo criador e fonte de novas transformações e gerações. Palavras que retratam a sociedade romana à beira da destruição material e moral, “com a sua sordidez e vaidades", constituída por "pessoas com os olhos fracassados, sintoma de suas almas sombrias", que se transformaram quase que milagrosamente por divinas lentes, e que produziram, a consagrada obra literária Resurrezione di Roma-dialoghi interdisciplinari su cittá, persona e relazioni a partire da um testo di Chiara Lubich, em português, Ressurreição 
de Roma - diálogos interdisciplinares sobre cidade, pessoa e relações a partir de um texto de Chiara Lubich. No entanto, para Chiara Lubich não era suficiente esse olhar amoroso voltado somente para Roma, tanto que, em um artigo publicado na revista italiana Cittá Nuova intitulado Una cittá non basta, em português "Uma cidade não é suficiente”, a autora expressa a aspiração de uma humanidade refeita após a catástrofe. Diz ela: “uma cidade é muito pouco ... aspira algo maior - tua pátria, a pátria de todos, ao mundo." Para ela não se trata de uma utopia, pois "esta cidade está presente nas demais e todos a podem ver, desde que o olhar se alicerce em Deus, descartando a nossa alma e acendendo o fogo divino".

Gostaríamos de concluir com algumas reflexões sobre a velhice e a proximidade da conclusão do ciclo assim denominado vida, não a apresentando como uma fase solitária que gera angústia e tristeza ou mesmo que retira o colorido das horas e dos dias, ou ainda que rouba alegrias e encantamentos, produzindo no homem sensações de abandono e isolamento. Pelo contrário, o texto e a metáfora que se seguem, descortinam a velhice como uma áurea fase de fertilidade e criatividade, produtora de misteriosos frutos de sabedoria. A velhice, se encarada como proximidade da morte, falência de ideais e de paixões, riscos que se assemelham a quedas em um abismo, pode se assemelhar ao período de pandemia no qual vivemos. Meditemos o texto do conhecido humanista italiano IGINO GIORDANI (1894-1980), escritor, jornalista e político, em seu Diário di Fuoco, em português, Diário de Fogo, no qual desvenda o seu elevado espírito, em aparente contraste com o inverno da vida. Para ele, a velhice nada mais é do que "o destino da árvore frutifera" que "pode se comparar com a vida do homem, que produz frutos na sua estação fecunda. Enquanto floresce, ao seu redor há cantos e gorjeios, brisas e sol; e, quando amadurece seus frutos, toda a natureza profusamente o envolve com calor. Depois, os agricultores se retiram para os refeitórios e palheiros, e, após algumas palpitações de vida e de cor no outono, sucede o frio silêncio, debaixo do plúmbeo céu, lançando suas folhas como lágrimas supremas que caem sobre a terra. O mesmo acontece com o homem quando superou a idade de maior produção. Caem desilusões e amizades, como as folhas, e o silêncio envolve o seu entorno tornando triste a paisagem: ele aos poucos permanece só a contemplar, espectador mudo, a sua ruína que avança. No entanto, assim como naquele frio e naquela solidão a árvore prepara nova primavera, concentrando calor e linfa, também o homem pode fazer daquela invernal redução de amigos e de energias, a concentração do vigor impregnado de uma nova existência; utilizar aquele abandono dos homens para aderir a Deus, preencher aquele afastamento humano com a graça divina; e então, envolvido no silêncio de ingratidões e avarezas e muito além da aparente velhice frágil e gélida, satisfazerse plenamente com o calor de Deus, elevar-se interiormente enquanto diminui externamente; 
oferecer aos homens um fruto que não se calcula na economia, mas se funda na teologia. Iniciase no inverno do homem, a primavera de Deus. " (Diario di fuoco, Città Nuova editrice, páginas 48/49). 